\title{
SIRT4 controls the balance between lipid synthesis and catabolism by repressing malonyl- CoA decarboxylase
}

\author{
Gaëlle Laurent ${ }^{1}$, Natalie J German ${ }^{1}$, Asish K Saha², Vincent CJ de Boer ${ }^{1,3}$, Frank Fischer ${ }^{4}$, Gina Boanca ${ }^{4}$, \\ Noah Dephoure ${ }^{5}$, Bhavapriya Vaitheesvaran ${ }^{6}$, Michael Davies', Steven P Gygi ${ }^{5}$, Deborah M Muoio ${ }^{7}$, \\ Irwin J Kurland ${ }^{6}$, Clemens Steegborn ${ }^{4}$, Neil B Ruderman ${ }^{2}$, Marcia C Haigis ${ }^{{ }^{*}}$
}

From Metabolism, diet and disease

Washington, DC, USA. 29-31 May 2012

Lipid metabolism is highly controlled by the nutritional state of the organism. In this study, we identify the mitochondrial sirtuin, SIRT4, as a critical regulator of lipid homeostasis. We find that SIRT4 represses fatty acid oxidation while promoting lipid anabolism. Mechanistically, SIRT4 regulates this balance by inhibiting malonyl-CoA decarboxylase (MCD), an enzyme that produces acetylCoA from malonyl-CoA, a precursor for lipogenesis that also inhibits mitochondrial fat oxidation. We find that SIRT4 is active in nutrient-rich conditions, such as in the fed state. As a consequence, SIRT4 null mice display reduced levels of malonyl-CoA in skeletal muscle and white adipose tissue in the fed state and fail to further lower malonyl-CoA levels during fasting. SIRT4 null mice possess a catabolic signature of lipid metabolism and demonstrate decreased de novo lipogenesis. These studies highlight SIRT4 as a novel regulator of MCD activity and malonyl-CoA levels, providing new insight into the regulation of lipid homeostasis.
W. Stedman Nutrition and Metabolism Center, Duke University Medical Center, Durham, NC27710, USA.

Published: 1 June 2012
doi:10.1186/1753-6561-6-S3-P30

Cite this article as: Laurent et al:: SIRT4 controls the balance between lipid synthesis and catabolism by repressing malonyl-CoA decarboxylase. BMC Proceedings 2012 6(Suppl 3):P30.

\section{Author details}

'Department of Cell Biology, The Paul F. Glenn Labs for the Biological Mechanisms of Aging, Harvard Medical School, Boston, MA 02115, USA ${ }^{2}$ Diabetes Research Unit, Section of Endocrinology, Department of Medicine, Boston University Medical Center, Boston, MA 02118, USA. ${ }^{3}$ Current address: Laboratory Genetic Metabolic Diseases, Academic Medical Center, Amsterdam, 1105AZ, The Netherlands. ${ }^{4}$ Department of Biochemistry, University of Bayreuth, 95447 Bayreuth, Germany. ${ }^{5}$ Department of Cell Biology, Harvard University Medical School, Boston, MA 02115, USA ${ }^{6}$ Department of Medicine, Diabetes Center, Stable Isotope and Metabolomics Core Facility, Albert Einstein College of Medicine, Bronx, New York 10461, USA. ${ }^{7}$ Departments of Medicine and Pharmacology \& Cancer Biology, Sarah

Submit your next manuscript to BioMed Central and take full advantage of:

- Convenient online submission

- Thorough peer review

- No space constraints or color figure charges

- Immediate publication on acceptance

- Inclusion in PubMed, CAS, Scopus and Google Scholar

- Research which is freely available for redistribution
() Biomed Central 